\title{
Comparative Analysis of Proposed Photovoltaic-Grid and Grid-Only Systems for Uninterrupted Charging of Plug-in Electric Vehicles
}

\author{
Abdul Rauf Bhatti ${ }^{1}$ (D) Arslan Dawood Butt $^{1}$ (D) $\cdot$ Yawar Ali Sheikh $^{1}$ (D) Kashif Nisar Paracha $^{1}$ (D) Naila Zareen ${ }^{2}$ (D) \\ Received: 15 October 2020 / Accepted: 22 April 2021 / Published online: 8 May 2021 \\ (C) The Author(s), under exclusive licence to Springer Nature Singapore Pte Ltd. 2021
}

\begin{abstract}
Currently, uninterrupted charging of Electric Vehicle (EV) is not possible due to grid overloading during day-time. The interruptions during charging causes uncertainty for users. This work proposes a solution to this vehicle charging problem by introducing a combination of Energy Storage Unit (ESU) and Photovoltaic (PV) panel charging along with the grid. The proposed solution is efficient in providing charging for EVs without any interruption in an office parking scenario. The important benefit of the proposed system is the rapid fulfillment of the charging demand of all EVs in parallel to lessening the added grid burden. The control algorithm is designed according to deterministic rule-based schemes. The proposed work is valid for the areas where parity level has already been reached. The efficacy of the proposed technique is evaluated under different charging situations using Matlab simulations. The results show that all connected EVs are charged fully without interruption. Moreover, the simulation results prove that EV charging using the proposed system lowers the added burden from the grid up to $98.6 \%$. This work is envisioned to offer stimulating research prospects in the area of vehicle charging using grid-connected renewable sources.
\end{abstract}

Keywords Interruption-less charging $\cdot$ Electric vehicles $\cdot$ Pv system $\cdot$ Energy storage unit $\cdot$ Renewable energy

\section{Introduction}

The rise of greenhouse gasses and their imminent environmental impacts have accelerated the research on Renewable Energy (RE) sources [1, 2]. It has been established that one of

This article is part of the Topical Collection on Advances in Energy Optimization.

Arslan Dawood Butt

arslandawood@gcuf.edu.pk

Abdul Rauf Bhatti

bhatti_abdulrauf@gcuf.edu.pk

Yawar Ali Sheikh

yawarali@gcuf.edu.pk

Kashif Nisar Paracha

kashifnisar@gcuf.edu.pk

Naila Zareen

syedanailazareen@gmail.com

1 Department of Electrical Engineering and Technology, Government College University Faisalabad, Faisalabad, Pakistan

2 Karachi Institute of Power Engineering, Pakistan Institute of Engineering and Applied Sciences, Karachi, Pakistan the main sources of pollution is the greenhouse gasses and $\mathrm{CO}_{2}$ emissions from the conventional Internal Combustion Engine (ICE) vehicles. The growing interest of researchers in Electric Vehicles (EVs) depicts the general trend to reduce the dependency on ICE vehicles. The main link between EVs and the electric grid is the charging of the batteries. Due to the easiness and availability of unrestrained energy from the grid, direct charging of EVs from the grid is extensively adopted. The charger only requires a simple power outlet that provides EV users with easy access to the charging point Yilmaz and Krein [3]. Conversely, charging directly from the grid generates an added load for the electric grid. This is predominantly critical during the peak (day time) hours when the electrical energy demand is very high. The consequences are distribution losses, degradation in the power quality and voltage deviation due to the congestion of the grid (Akhtar et al. [4]; Sundstrom and Binding [5]). As per Electric Power Research Institute (EPRI), the overall electricity consumption due to plug-in hybrid EVs is expected to increase by $300 \mathrm{TWh}$ from the year 2030 to 2050 Duvall et al. [6]. However, in countries where the climate is hot and the sun shines a larger part of the day, roofing parking lots with PV plates protect from sun and rain in addition to the renewable energy which facilitates the vision of "charging while parking" (Esfandyari 
et al. [7]; Van Roy et al. [8]) and an ideal setup for office environment can be achieved. Another impetus to incorporate PV is the sharp decline in the price of modules; the cost for photovoltaic generators has dropped by more than $50 \%$ between 2010 and 2014 Tripathi et al. [9]. Another preferable option is to combine PV array and Energy Storage Unit (ESU) to deal with fluctuated power (Bhatti et al. [10]; Bhatti et al. [11]; Zakeri and Syri [12]). To increase stability of such power systems, multiple system level optimization techniques have been developed specifically for scenarios where Fuel cells are used as ESUs (Fan et al. [13]; Razmjooy et al. [14]; Yanda et al. [15]; Yu et al. [16]; Yuan et al. [17]). However, the hybridization of the sources (PV, ESU, and grid) increases the complexity of the system. Moreover, optimizing the performance of the hybrid system in the presence of intermittent PV power and volatile grid electricity prices is a difficult task. Furthermore, the system must meet the random EV demand while reducing the grid burden.

Inevitably, to effectively utilize the energy sources, an efficient and intelligent scheme for the proper energy management is required. The purpose is to manage the interactions among the system components, as well as to deal with the various uncertainties, namely the random EV power demand, PV intermittency and variation in the grid energy prices (García-Triviño et al. [18]; Ramadhani et al. [19]). The scheme can be embedded into a controller for real-time execution; thus, the charging station can be automatically operated without the presence of human operators (Liu et al. [20]; Liu et al. [21]). A summary of various literature-based PV-grid type EV charging schemes incorporating rule-based algorithms alongside their distinct features is presented in Table 1.

Though the literature-based EV charging schemes described in Table 1 reduces grid burden and charging price, they are not resilient in conjoining the important charging features such as interruption-less charging during daytime and valley filling operation. The primary reason for this is because uninterrupted charging without considering Vehicle to Grid (V2G) or Vehicle to Vehicle (V2V) operations can cause overloading of the grid especially during the daytime. Furthermore, V2G and V2V operations are also undesirable for the EV owner as this increases the number of charging cycles of the EV's battery reducing its lifespan. In this context, the proposed scheme has been developed to achieve uninterrupted daytime EV charging with valley filling operation without V2G and V2V operation. The performed simulations in this work to estimate the performance of the proposed charging scheme considers the location of an office parking area during day-time.

The proposed work provides an un-interrupted EVs charging by making use of the PV-grid combination throughout office hours in contrary to the traditional grid alone charging. In addition, the proposed strategy helps to reduce the additional EV charging burden on the utility grid up to $98.6 \%$.

In Section 2 of this work, the system model used to estimate the performance of the proposed rule-based energy management scheme has been described. The main operational flow of the scheme itself has been elaborated in Section 3 . Section 4 describes the simulation results obtained in this work for the office parking lot environment during different days of the year including summer, winter and holiday. The final concluding remarks are provided in Section 5.

\section{Modeling of Proposed System}

\section{System Components}

To simulate the proposed system, it is inevitable to model a PV-grid charging system. For this purpose, the components of charging system are modeled first as shown in Fig. 1. Here both grid and the ESU are connected to the DC bus using bidirectional power converters. However, as V2V and V2G operations are not performed in our work, only uni-directional DC charger has been connected to charge the EV.

Table 1 Comparison of literature-based EV charging schemes with proposed scheme

\begin{tabular}{|c|c|c|c|c|c|c|c|c|}
\hline \multirow{2}{*}{$\begin{array}{l}\text { Reference and } \\
\text { Year }\end{array}$} & \multicolumn{3}{|c|}{ Charging Station } & \multicolumn{5}{|c|}{ Characteristics of Smart Charging Schemes } \\
\hline & $\begin{array}{l}\text { PV- } \\
\text { grid }\end{array}$ & $\begin{array}{l}\text { Decentralized } \\
\text { Control }\end{array}$ & $\begin{array}{l}\text { Workplace } \\
\text { Parking }\end{array}$ & $\begin{array}{l}\text { Daytime } \\
\text { Charging }\end{array}$ & $\begin{array}{l}\text { Uninterrupted } \\
\text { Charging }\end{array}$ & $\begin{array}{l}\text { No V2G and V2V } \\
\text { operations }\end{array}$ & $\begin{array}{l}\text { Valley-filling } \\
\text { Operation }\end{array}$ & $\begin{array}{l}\text { Rule-based } \\
\text { Algorithm }\end{array}$ \\
\hline$[21]$ & $\checkmark$ & $\times$ & $\checkmark$ & $\times$ & $\checkmark$ & $\checkmark$ & $x$ & $\checkmark$ \\
\hline$[18]$ & $\checkmark$ & $\checkmark$ & $\times$ & $x$ & $\checkmark$ & $\checkmark$ & $x$ & $\checkmark$ \\
\hline$[10]$ & $\checkmark$ & $\checkmark$ & $\checkmark$ & $\checkmark$ & $x$ & $\checkmark$ & $x$ & $\checkmark$ \\
\hline$[22]$ & $\checkmark$ & $x$ & $\times$ & $\checkmark$ & $\checkmark$ & $\checkmark$ & $x$ & $\checkmark$ \\
\hline$[23]$ & $\checkmark$ & $x$ & $\checkmark$ & $\checkmark$ & $x$ & $\checkmark$ & $\checkmark$ & $\checkmark$ \\
\hline$[24]$ & $\checkmark$ & $x$ & $\checkmark$ & $\checkmark$ & $\times$ & $\times$ & $\times$ & $\checkmark$ \\
\hline $\begin{array}{l}\text { Proposed } \\
\text { scheme }\end{array}$ & $\checkmark$ & $\checkmark$ & $\checkmark$ & $\checkmark$ & $\checkmark$ & $\checkmark$ & $\checkmark$ & $\checkmark$ \\
\hline
\end{tabular}


Fig. 1 PV to EV system model

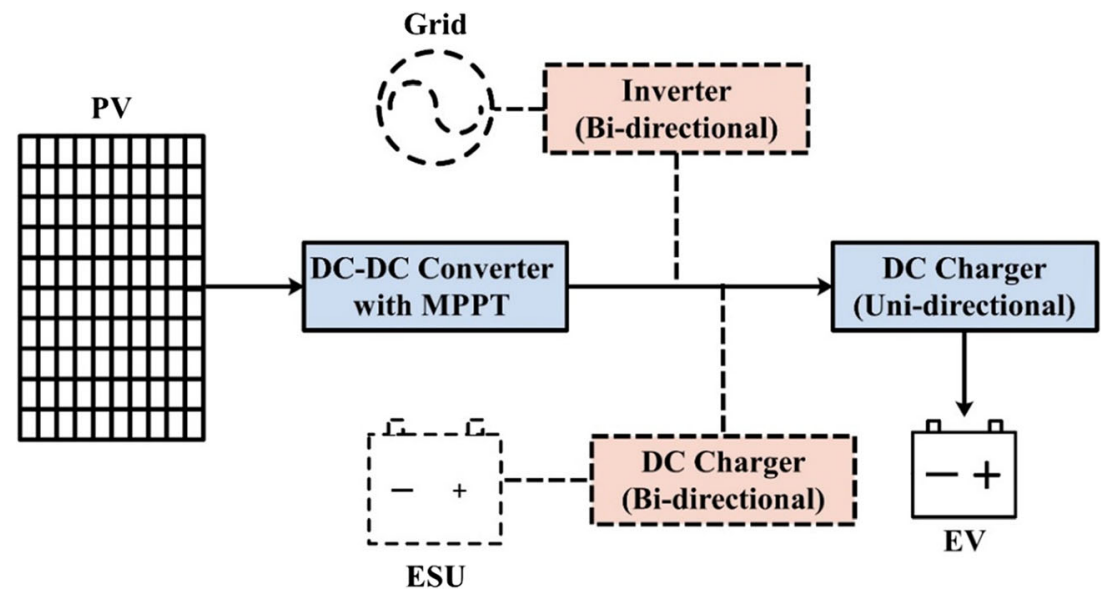

\section{Power Demand of EV}

The mathematical model used in this work to simulate power demand of EV ( $\left.E V \_D m d\right)$ is as described in Shao et al. [25]. Using this model, the power requirement of any individual EV connected to the grid can be calculated at time $t$ using Eq. [1].

$P_{e v, t}=P_{e v, r e q} \times S_{t} \times w_{t} \times c_{t}$

Here, in time step $\Delta \mathrm{t}, P_{e v, r e q}$ shows the charging power measurements which are required by the EV's battery to upsurge between the state of charge ( $\mathrm{SOC} 0$ ) and maximum (SOCmax) conditions. To check SOC, Variable St is used as a control signal. Whereas office working days and working hours are shown by wt and ct respectively. For a large number of EVs connected to the charging station, the summation of
$P_{e v, t}$ is for the total EV_Dmd is shown in Eq. [2].

$$
E V \_ \text {Dmd } d_{t}=\left\{\begin{array}{l}
\sum_{n=1}^{N} P_{e v, t}^{n},(t=9,10, \ldots, 18) \\
0, \quad \text { else }
\end{array}\right.
$$

Since the scheme is intended to be used for daytime charging, the office working hours are assumed to be between hours 0900 to 1800 . For the same office hours, EV Dmd is produced, to fulfil the need during the mentioned hours. Zhang et al. [26]. The PV output power is determined by using the single diode model (Ahmed and Salam [27]; Ahmed and Salam [28]). The output PV current $I_{p v}$ can be attained in Eq. [3], by assuming available values of Temperature (T) and solar irradiance $(G)$.

$I_{p v}=\left[\left(I_{S C_{S T C}}+k_{i}\left(T-T_{S T C}\right)\right) \frac{G}{G_{S T C}}\right]-I_{0}\left[e^{\left(\frac{v_{p v}+I_{p v} R_{S}}{V_{T}}\right)}-1\right]-\left(\frac{V_{p v}+I_{p v} R_{S}}{R_{P}}\right)$

Where $I_{o}$ is the diode's saturation current; $I_{S C_{-} S T C}$ is the short circuit current at STC $\left(G_{S T C}=1000 \mathrm{~W} / \mathrm{m}^{2}, T_{S T C}=\right.$ $298 \mathrm{~K}) ; k_{i}$ is the short circuit current coefficient; $V_{T}=a k T /$ $q$ is the thermal voltage; $q$ is electron charge $(1.602 \times$ $\left.10^{-19} \mathrm{C}\right) ; a$ is the ideality factor $(1<a<2)$ Ishaque and Salam [29]; $k$ is Boltzmann constant $\left(1.381 \times 10^{-23} \mathrm{~J} / \mathrm{K}\right)$. The $R_{S}$ shows the series whereas $R_{P}$ shows the shunt resistances respectively. Newton-Raphson iteration method for its rapid convergence, is used to solve Eq. [3] because of its transcendental nature, by varying the output voltage $\left(V_{p v}\right)$ from zero to maximum open circuit voltage Ishaque et al. [30]. The (Vpv) can be concluded as its final value equal to the voltage at Maximum Power Point (MPP). By assuming that there is no partial shading and the inverter is functioning at MPP, the single module output power can be formulated by Eq. [4]
$P_{p v}=\max \left(I_{p v} \times V_{p v}\right)$

where $V_{p v}$ is the PV module output voltage. At this stage, we can calculate the entire power of the PV array (PV_Pwr) by using Eq. [5].

$P V \perp w r=P_{p v} \times N_{p v}$

where Npv is the number of PV modules used in the array. In this work, Kyocera's KD325GX-LFB, which is a $325 \mathrm{~W}$ polycrystalline PV module, has been considered to form PV arrays. The data values of for irradiance $(\mathrm{G})$ and ambient temperature $(\mathrm{T})$ are collected for the National Renewable Energy Laboratory (NREL) located in Southern part of California (GPS: $33.966674^{\circ} \mathrm{N}$, $18.42282^{\circ} \mathrm{W}$ ) (García-Triviño et al. [18]; Hsu et al. [31]; Stoffel and Andreas [32]). 


\section{The Energy Storage Unit (ESU) Model}

For the approximate calculations of SOC of the ESU, the model is taken from Belfkira et al. [33].

$\operatorname{SOC}(t)=\operatorname{SOC}(t-1) \cdot\left(1-\delta_{\text {bat }}(t)\right)+\left(\frac{P_{B}(t)}{V_{\text {bus }}}\right) \cdot \eta_{\text {bat }} \cdot \Delta t$

In Eq. [6], $\delta$ bat(t) is the self-discharge rate, calculated on hourly basis. It is considered to be zero for practical purposes. The $\eta$ bat denotes the efficiency of charging and discharging of the battery, which in both cases, is supposed to be $100 \%$. The voltage of dc common bus is shown by Vbus; in this scenario, Vbus $=500 \mathrm{~V} ; \mathrm{PB}(\mathrm{t})$ shows the charging or discharging power. The value of $\mathrm{PB}(\mathrm{t})$ varies with respect to the available and required ESU Power. In this model, Req_ESU_Pwr parameter represents the required ESU power (in $\mathrm{kW}$ ) which is needed to raise ESU's SOC from starting levels to the upper limit (SOCU) in the prescribed $\Delta \mathrm{t}$ time step. This Req_ESU_Pwr is described in Eq. [7].

$\operatorname{Req} \_S S E_{-} P w r(t)=\frac{(S O C U-S O C(t)) \times C_{b a t} \times N_{b a t}}{\Delta t}$

Similarly, ESU can provide continuous power for time step $\Delta t$, before it reaches from its SOC to its lower limit (SOCL), this continuous power of ESU is the maximum amount of power (in kW); shown as available ESU power (Avl_ESU_Pwr). It is characterized as

$A v l \_E S U P w r(t)=\frac{(S O C(t)-S O C L) \times C_{b a t} \times N_{b a t}}{\Delta t}$

In Eq. [7] and Eq. [8], Nbat represents the total batteries available in the ESU, whereas Cbat is considered as apparent value of the capacity of a single battery. To get the maximum longevity from the batteries, the battery charging and discharging states should be restricted as per the mentioned SOCL and SOCU limits. Which are set as $10 \%$ and $100 \%$, respectively Li et al. [34].

\section{Operational Flow of Rule-Based Scheme}

The scheme proposed in this work has been developed using several rule-based strategies. The rules may be taken as two cases of simple 'if-then' statements, in which the 'if' cases are connected to the different situations and 'then' cases implement the operational modes. The overall operational flow of the charging station can be described in terms of four main scenarios. These main scenarios are primarily developed around the availability of renewable power PV Pwr and the energy demand represented by EV Dmd. However, in addition to these main scenarios, a few additional scenarios may also occur. These additional scenarios depend on variables like the price of electricity being provided by the grid (GE_Pr) and the level of stored energy in ESUs (SOC). Thereby, to meet the targets set for the scheme, charging station's operation under each scenario may simultaneously utilize more than one operation modes. The primary four scenarios used in our scheme are the following;

- Overload, when EV Dmd > PV_Pwr.

- Underload, when EV_Dmd is present but EV_Dmd is $\leq$ PV_Pwr.

- No-load, when PV_Pwr is available but the EV_Dmd $=0$. - Idle, when both EV_Dmd $=0$, and PV_Pwr $=0$.

By using the outputs of already developed sub-models, the PV-grid charging station is simulated using scheme. The objective of the scheme-based control is to charge the EVs of office employees without interruption. Since the scheme is exclusively intended to aid the office employees without concerns of generating revenue from the charging station, the proposed scheme operates the charging station on 'break even'. The 'break even' strategy will facilitate the EV user with lowest charging price as possible and also care for the charging station of bearing financial distress. For this purpose, it is crucial to find the optimum size of charging station under which resilient operation of scheme could be realized without experiencing financial losses to the station. The main flow of PV-grid operation under the control of scheme is given in the form of the flowchart as shown in Fig. 2.

In this flowchart the four main operating scenarios are shown with diamond shapes and the possible operating modes under each scenario are mentioned in the boxes. To simulate the operation of charging station, the scheme algorithm requires eight inputs: i) PV_Pwr (kW), ii) SOC of ESU $(\mathrm{kW})$, iii) EV_Dmd (kW), iv) GE_Pr (cents/kWh), v) PV_Pr (cents/ $\mathrm{kWh})$, vi) ESU_Pr (cents/kWh), vii) List of holidays and viii) date (dd/mm/yyyy). A yearlong database consisting the hourly values of PV_Pwr, EV_Dmd and GE_Pr are generated with the help of developed sub-models of the PV-grid system Chen and Duan [35]. The database is loaded within the scheme algorithm to use for the simulation of the charging station. Although, the SOC is represented in percentage but it is differently defined here in terms of power to hold the similarity of plotting parameters (that is PV_Pwr, EV_Dmd, SOC). Thus, it is represented as $S O \bar{C}=\% S O C(t) \times C_{b a t} \times$ $N_{b a t}$ which can be defined as, the maximum amount of power (in $\mathrm{kW}$ ) which ESU can deliver continuously for one hour. Initially, the SOC of ESU is considered to be $30 \%$ which will be changing after every hour of operational job under the given particular circumstances Maleki et al. [36]. Similarly, PV_Pwr, GE_Pr, and EV_Dmd are changing with the new value in every hour of simulation.

To specify the simulation period, the scheme algorithm asks the user to enter a couple of dates at the beginning of 


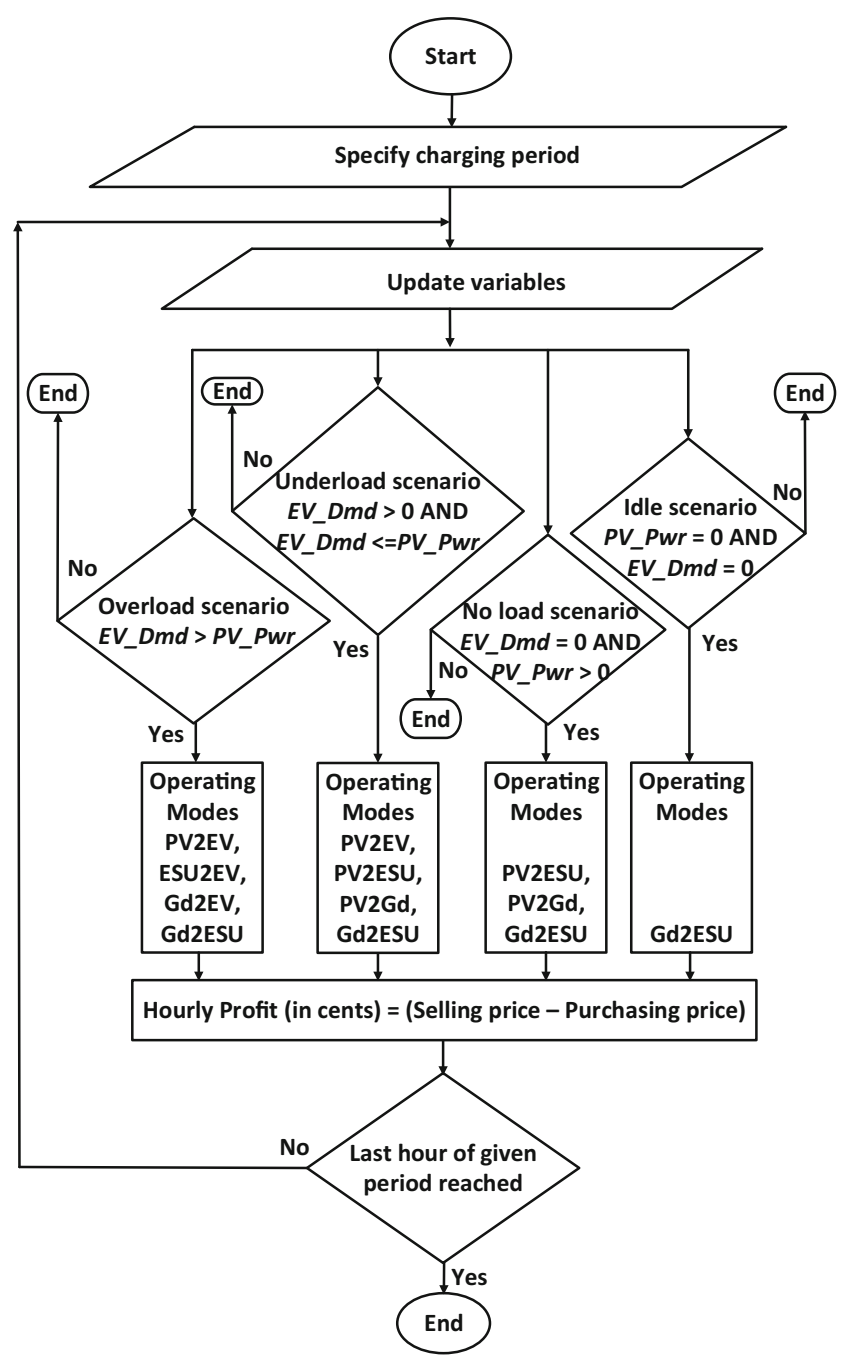

Fig. 2 Simplified flowchart for proposed scheme to charge EVs

the simulation. This duration can be varied from one day up to one year for this research. According the provided input duration of the user, the database is loaded and the information is extracted from the database as per the input period. The office working days are confirmed by comparing the user specified dates with the preloaded list of holidays. Moreover, on office working days, the office working hours are considered to be from 9:00 am to 6:00 pm (Locment and Sechilariu [22]; Mohamed et al. [37]; Zhang et al. [26]). After every hour of the operation, the prices of energy selling and purchasing are calculated based on the predefined rules. The difference of the prices of energy selling and purchasing gives the amount of hourly profit in cents.

\section{Results and Discussions}

Figure 3 shows the variations of EV charging station's performance parameters for a single day $(15 / 01 / 2013)$ once $150 \mathrm{EVs}$ are charged using proposed scheme under the condition of par parity level (PL). Here, PL means that PV_Pr $=$ Avg_GE_Pr. As the weather conditions are clear on this particular day, there are no abrupt fluctuations of the PV_Pwr in Fig. 3(a) and it has a rather smooth profile. Though PV_Pwr is sufficient to meet the EV_Dmd during the peak irradiance time from 10 to 18 , this is not possible outside such times as the solar irradiance and consequently PV_Pwr drop below EV_Dmd levels. Thereby, outside this time zone, PV2EV (PV energy to charge EV) operating mode of the proposed scheme cannot be implemented. To maintain interruption less charging of the EVs in these hours, ESU2EV (ESU energy to charge EV) and Gd2EV (grid energy to charge EV) operational modes are utilized.

From Fig. 3(b), it is clear that the system is in underload scenario from 10 to $18 \mathrm{~h}$. During this time EV_Dmd is met with PV_Pwr using mode PV2EV and has been labeled as "Uninterrupted charging using PV only". From hours 9 to 10 and 18 to 19 , the system is in overloading condition i.e. the PV_Pwr is not sufficient to meet EV_Dmd. Thereby, other available energy resources must be utilized. During the beginning of office hours from 9 to 10, the EV_Dmd is so high that in addition to the combination of both PV2EV and ESU2EV, Gd2EV is also utilized to maintain interruption less charging. This has been labeled as "Uninterrupted charging using PV, ESU and grid".in Fig. 3(b). During the evening at the end of
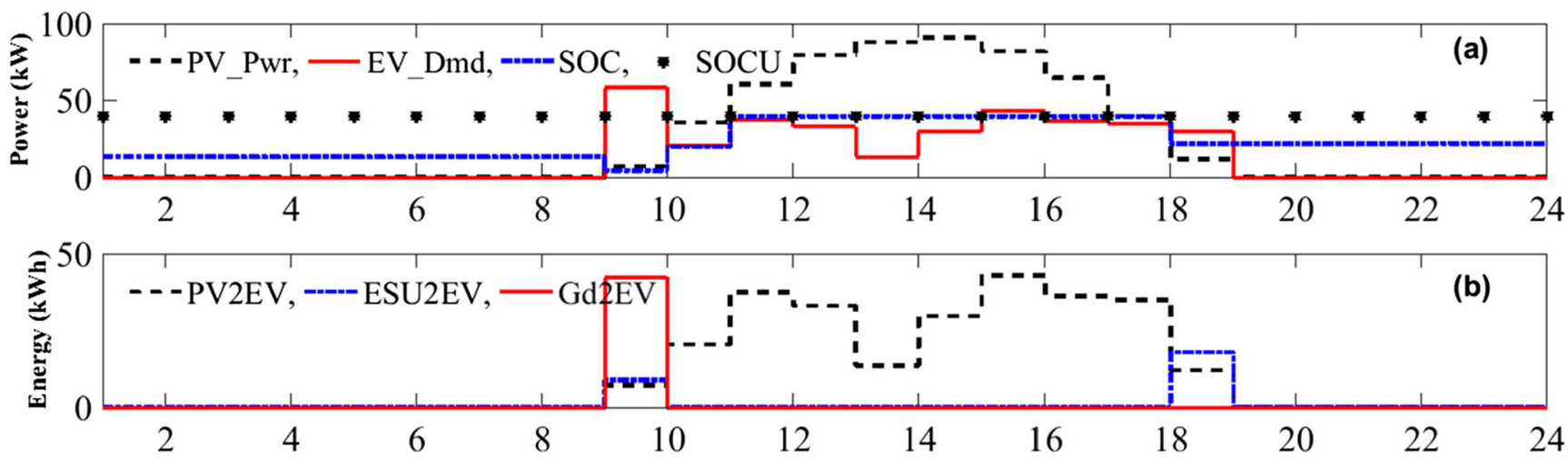

Fig. 3 The results of proposed scheme for $150 \mathrm{EVs}$ at PL on 15th January 

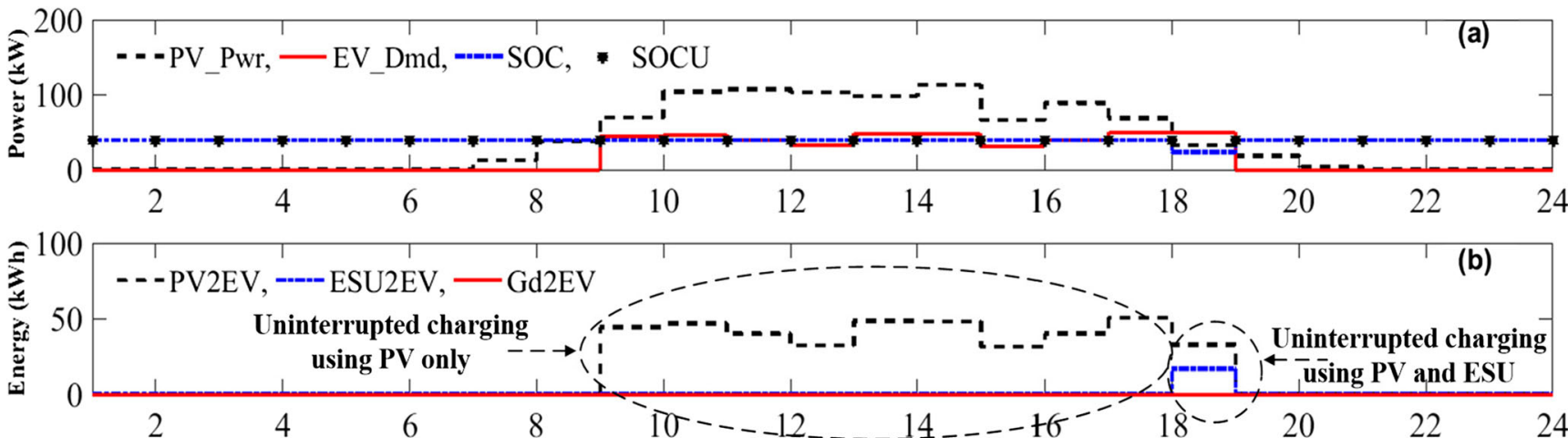

Fig. 4 The results of proposed scheme for $150 \mathrm{EVs}$ at PL on 11th June

office hours from 18 to 19 , the uninterrupted EV charging operation is maintained by implementing PV2EV with remaining demand met via ESU2EV operating mode. This scenario has been labeled as "Uninterrupted charging using PV and ESU" in Fig. 3(b). Here, the sequence of PV2EV and ESU2EV is followed instead of PV2EV and Gd2EV because grid is overloaded (that is GE_Pr $>$ ESU_Pr).

Figure 4 shows the results of charging $150 \mathrm{EVs}$ for a specific day (11/06/2013) in summer. It is to be noted that the PV produces more power compared to the winter day. As the days in summer are long, the power started to be generated by PV before the office working hours and carry on to be produced even after the closing office hours. This is depicted in the
Fig. 4(a). The additional PV_Pwr lessens the grid reliance by restricting the triggering of $\mathrm{Gd} 2 \mathrm{EV}$ as illustrated by the Fig. 4(b). Additionally, the excess PV_Pwr compensates the system financial losses by selling the surplus energy to the grid using mode PV2Gd.

During low irradiance, for example, during the hours 18 to 19, the ESU is activated to meet the EV_Dmd using mode ESU2EV which is labeled as "Uninterrupted charging using PV and ESU". Although the ESU loses its energy during ESU2EV mode, it is regained during hour 19 to 20 via mode PV2ESU when PV_Pwr exceeds EV_Dmd.

Figure 5 shows the operation for a specific (01/01/2013) holiday. Figure 5(a) reveals the no load scenario, where the
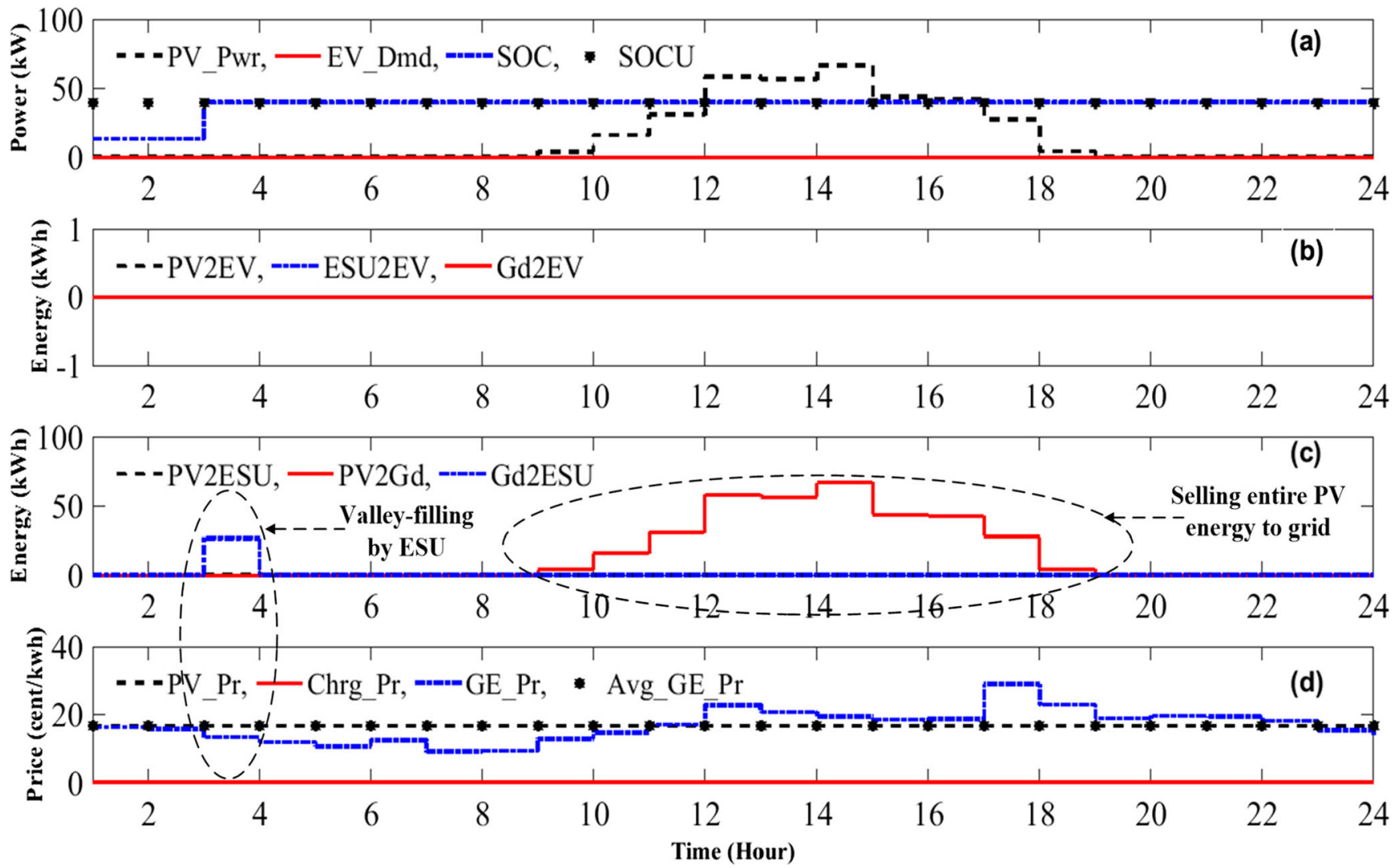

Fig. 5 The results of proposed scheme during holidays at PL on 1st January 
Table 2 Average grid burden by proposed PV-Grid scheme and Grid-Only scheme at $0.83 \mathrm{PL}$

\begin{tabular}{lll}
\hline $\begin{array}{l}\text { Average EV charging load on grid during peak hours }(\mathrm{kW}) \\
\text { Grid Only }\end{array}$ & $\begin{array}{l}\text { Decrease in EV load on grid using } \\
\text { proposed scheme (\%) }\end{array}$ \\
\hline 35.4 & 0.5 & 98.6 \\
\hline
\end{tabular}

PV_Pwr is available but no EV to be charged due to office holiday. However, once the ESU reaches the SOCU limit, it remains constant throughout the day as shown in plot Fig. 5(a).

Since there is no EV to be charged throughout the day, the entire PV Pwr is sold out to the grid via mode PV2Gd, as shown in Fig. 5(c) circled as "Selling entire PV energy to grid". This is the main income that compensates the economic losses which the charging station has to endure. The energy sold during the holidays is more prominent during summer when PV_Pwr is available abundantly and the selling price to the grid is high.

As already mentioned, the proposed solution is applicable for areas which are at par or below parity levels. It is worth mentioning that par parity is the level when price of electricity from PV system is equal to average grid electricity price and below parity means when PV based price is less than grid price. Table 2 shows average burden on grid due to charging of EVs using Grid-Only charging as well as using proposed solution of EV charging under the conditions of below parity, that is PV_Pr is 0.83 times of Avg_GE_Pr.

On the basis of results presented in this section, it is clear that the proposed scheme technique is capable of providing interruption less EV charging with valley filling operation in an office parking environment. It is also clear from the results in Table 2 that burden of EV charging on grid is reduced up to $98.6 \%$ compared to burden without applying proposed solution. The proposed scheme is based on simple: if-then: statements and thereby requires very little computational resources. Furthermore, the reduced complexity of the algorithm makes it possible to implement it in run time as compared to other optimization-based algorithms Saqib et al. [38]. However, in our scenario, system sizing needs to be determined a prior for different geographical locations to ensure that sustained interruption-less charging is feasible.

\section{Conclusion}

In this paper, a novel technique is presented for the charging of EVs during the day-time by making use of the charging station based on PV-grid combination. The proposed technique scheme, which constitutes schemes that are deterministic rule-based, helps the charging station to provide continual charging. The rule-based schemes provide an efficient solution compared to meta-heuristic schemes when real time data is being processed. However, unlike meta-heuristic algorithms, the rule-based schemes have to re-write to solve every new problem. The proposed scheme has been simulated on a typical system in office parking environment. The results show that EVs charging by making use of the PV-grid combination along with the proposed strategy remains uninterrupted throughout the time as compared to the traditional grid alone charging. In addition, the proposed strategy helps to reduce the additional EV charging encumbrance on the utility grid up to $98.6 \%$. It is anticipated that the proposed technique will offer interesting and encouraging research avenues for EV charging by exploiting renewable energy sources. Since the proposed work is applicable for areas having par and below parity conditions, this work could be further extended in future by considering the above parity conditions. More so, this work (which is deterministic rule-based) could be replicated using fuzzy rule-based for comparison purposes.

Authors' Contributions All authors contributed equally in this work.

Data Availability The data is available with authors.

Code Availability The custom Matlab code is available with authors.

\section{Declarations}

Conflicts of Interest/Competing Interests The authors declare no conflict of interests.

\section{References}

1. Ahmed A, Al-Amin AQ, Ambrose AF, Saidur R (2016) Hydrogen fuel and transport system: a sustainable and environmental future. Int J Hydrog Energy 41:1369-1380

2. Hossain MF (2016) Solar energy integration into advanced building design for meeting energy demand and environment problem. Int $\mathrm{J}$ Energy Res 40:1293-1300

3. Yilmaz M, Krein PT (2012) Review of battery charger topologies, charging power levels, and infrastructure for plug-in electric and hybrid vehicles. IEEE Trans Power Electron 28:2151-2169

4. Akhtar Z, Opatovsky M, Chaudhuri B, Hui SYR (2019) Comparison of point-of-load versus mid-feeder compensation in LV distribution networks with high penetration of solar photovoltaic generation and electric vehicle charging stations. IET Smart Grid 2:283-292

5. Sundstrom O, Binding C (2011) Flexible charging optimization for electric vehicles considering distribution grid constraints. IEEE Transactions on Smart grid 3:26-37 
6. Duvall M, Knipping E, Alexander M, Tonachel L, Clark C (2007) Environmental assessment of plug-in hybrid electric vehicles EPRI, July 1

7. Esfandyari A, Norton B, Conlon M, McCormack SJ (2019) Performance of a campus photovoltaic electric vehicle charging station in a temperate climate. Sol Energy 177:762-771

8. Van Roy J, Leemput N, Geth F, Salenbien R, Büscher J, Driesen J (2013) Apartment building electricity system impact of operational electric vehicle charging strategies. IEEE Transactions on Sustainable Energy 5:264-272

9. Tripathi L, Mishra A, Dubey AK, Tripathi C, Baredar P (2016) Renewable energy: an overview on its contribution in current energy scenario of India. Renew Sust Energ Rev 60:226-233

10. Bhatti AR, Salam Z, Aziz MJBA, Yee KP (2016) A critical review of electric vehicle charging using solar photovoltaic. Int J Energy Res 40:439-461

11. Bhatti AR, Salam Z, Sultana B, Rasheed N, Awan AB, Sultana U, Younas M (2019) Optimized sizing of photovoltaic grid-connected electric vehicle charging system using particle swarm optimization. Int J Energy Res 43:500-522

12. Zakeri B, Syri S (2015) Electrical energy storage systems: A comparative life cycle cost analysis Renewable and sustainable energy reviews 42:569-596

13. Fan X, Sun H, Yuan Z, Li Z, Shi R, Razmjooy N (2020) Multiobjective optimization for the proper selection of the best heat pump technology in a fuel cell-heat pump micro-CHP system. Energy Rep 6:325-335

14. Razmjooy N, Razmjooy S, Vahedi Z, Estrela VV, de Oliveira GG (2021) A new Design for Robust Control of power system stabilizer based on moth search algorithm Metaheuristics and optimization in computer and electrical engineering :187-202

15. Yanda L, Yuwei Z, Razmjooy N (2020) Optimal arrangement of a micro-CHP system in the presence of fuel cell-heat pump based on metaheuristics. International Journal of Ambient Energy:1-12

16. Yu D, Wang Y, Liu H, Jermsittiparsert K, Razmjooy N (2019) System identification of PEM fuel cells using an improved Elman neural network and a new hybrid optimization algorithm. Energy Rep 5:1365-1374

17. Yuan Z, Wang W, Wang H, Razmjooy N (2020) A new technique for optimal estimation of the circuit-based PEMFCs using developed sunflower optimization algorithm. Energy Rep 6:662-671

18. García-Triviño P, Torreglosa JP, Fernández-Ramírez LM, Jurado F (2016) Control and operation of power sources in a mediumvoltage direct-current microgrid for an electric vehicle fast charging station with a photovoltaic and a battery energy storage system. Energy 115:38-48

19. Ramadhani UH, Shepero M, Munkhammar J, Widén J, Etherden N (2020) Review of probabilistic load flow approaches for power distribution systems with photovoltaic generation and electric vehicle charging. Int J Electr Power Energy Syst 120:106003

20. Liu N, Chen Q, Liu J, Lu X, Li P, Lei J, Zhang J (2014) A heuristic operation strategy for commercial building microgrids containing EVs and PV system. IEEE Trans Ind Electron 62:2560-2570

21. Liu N, Zou F, Wang L, Wang C, Chen Z, Chen Q (2016) Online energy management of PV-assisted charging station under time-ofuse pricing. Electr Power Syst Res 137:76-85

22. Locment F, Sechilariu M (2015) Modeling and simulation of DC microgrids for electric vehicle charging stations. Energies 8:43354356
23. Goli P, Shireen W (2014) PV powered smart charging station for PHEVs. Renew Energy 66:280-287. https://doi.org/10.1016/j. renene.2013.11.066

24. Ma T, Mohammed OA (2014) Optimal charging of plug-in electric vehicles for a car-park infrastructure. IEEE Trans Ind Appl 50: 2323-2330

25. Shao S, Pipattanasomporn M, Rahman S (2012) Development of physical-based demand response-enabled residential load models. IEEE Trans Power Syst 28:607-614

26. Zhang W, Ge W, Huang M, Jiang J (2015) Optimal day-time charging strategies for electric vehicles considering photovoltaic power system and distribution grid constraints Mathematical Problems in Engineering 2015

27. Ahmed J, Salam Z (2014) A maximum power point tracking (MPPT) for PV system using cuckoo search with partial shading capability. Appl Energy 119:118-130

28. Ahmed J, Salam Z (2015) An improved perturb and observe (P\&O) maximum power point tracking (MPPT) algorithm for higher efficiency. Appl Energy 150:97-108

29. Ishaque K, Salam Z (2011) An improved modeling method to determine the model parameters of photovoltaic (PV) modules using differential evolution (DE). Sol Energy 85:2349-2359

30. Ishaque K, Salam Z, Taheri H (2011) Accurate MATLAB simulink PV system simulator based on a two-diode model. Journal of power electronics 11:179-187

31. Hsu RC, Liu C-T, Chen W-Y, Hsieh H-I (2015) Wang H-L (2015) a reinforcement learning-based maximum power point tracking method for photovoltaic array. International Journal of Photoenergy 2015:1-12

32. Stoffel T, Andreas A (1981) NREL solar radiation research laboratory (srrl): baseline measurement system (bms); golden, Colorado (data). National Renewable Energy lab.(NREL), Golden, CO (United States),

33. Belfkira R, Zhang L, Barakat G (2011) Optimal sizing study of hybrid wind/PV/diesel power generation unit. Sol Energy 85:100 110

34. Li X, Hui D, Lai X (2013) Battery energy storage station (BESS)based smoothing control of photovoltaic (PV) and wind power generation fluctuations. IEEE transactions on sustainable energy 4:464-473

35. Chen C, Duan S (2014) Optimal integration of plug-in hybrid electric vehicles in microgrids. IEEE Transactions on Industrial Informatics 10:1917-1926

36. Maleki A, Ameri M, Keynia F (2015) Scrutiny of multifarious particle swarm optimization for finding the optimal size of a PV/ wind/battery hybrid system. Renew Energy 80:552-563

37. Mohamed A, Salehi V, Ma T, Mohammed O (2013) Real-time energy management algorithm for plug-in hybrid electric vehicle charging parks involving sustainable energy. IEEE Transactions on Sustainable Energy 5:577-586

38. Saqib M, Hussain MM, Alam MS, Beg MS, Sawant A (2017) Smart electric vehicle charging through cloud monitoring and management. Technology and Economics of Smart Grids and Sustainable Energy 2:18

Publisher's Note Springer Nature remains neutral with regard to jurisdictional claims in published maps and institutional affiliations. 